\title{
A importância da educação à distância na formação continuada do profissional de pedagogia.
}

\author{
The importance of distance education in training the pedagogy professional.
}

\author{
Aline Maganin Martins de Oliveira ${ }^{1}$
}

\begin{abstract}
RESUMO: O presente trabalho teve como objetivo analisar a importância da Educação à Distância na formação do profissional de Pedagogia. Mais especificamente, pretendeu-se conceituar e compreender as particularidades da Educação à Distância; Estudar a formação do pedagogo; analisar a importância da formação continuada. A metodologia consistiu na pesquisa bibliográfica; foram coletadas obras em formas de livros, artigos e materiais disponíveis na internet, em bases de dados como SciELO e Google Acadêmico. As obras foram analisadas e utilizadas aquelas que possuíam ligação direta com a temática estudada. A pesquisa se justifica por entender que as práticas da Educação à Distância deixaram de ser um assunto periférico e assumiu um lugar de destaque no cenário da educação brasileira e mundial. Considerando o pedagogo, compreende-se que esse profissional deve estar em constante formação, para que possa atuar de forma satisfatória tanto em ambientes escolares como em não escolares. Foi possível conceituar a Educação à Distância como uma modalidade de ensino não presencial, onde o processo de ensino e aprendizagem ocorre através do uso da internet e aparelhos tecnológicos. Muitos profissionais não conseguem conciliar o trabalho com os estudos, visto que as aulas no formato presencial exigem que os alunos frequentem fisicamente a instituição de ensino. A educação à distância permite que o aluno encontre o tempo adequado, assim como utilize o espaço físico disponível para se formar ou dar continuidade à sua formação.
\end{abstract}

PALAVRAS-CHAVE: Educação à Distância; Pedagogia; Formação Continuada.

\begin{abstract}
This study aimed to analyze the importance of Distance Education in the education of Pedagogy professionals. More specifically, it was intended to conceptualize and understand the particularities of Distance Education; Study the education of the pedagogue; analyze the importance of continuing education. The methodology consisted of bibliographic research; works were collected in the form of books, articles and materials available on the internet, in databases such as SciELO and Google Scholar. The works were analyzed and those that had a direct connection with the studied theme were used. The research is justified by understanding that the practices of Distance Education are no longer a peripheral subject and have assumed a prominent place in the scenario of Brazilian and worldwide education. Considering the pedagogue, it is understood that this professional must be in constant training, so that he can perform satisfactorily in both school and non-school environments. It was possible to conceptualize Distance Education as a nonclassroom teaching modality, where the teaching and learning process occurs through the use of the internet and technological devices. Many professionals are unable to reconcile work with studies, since classes in the face-to-face format require students to physically attend the educational

\footnotetext{
${ }^{1}$ Graduação em Licenciatura em Pedagogia pela Universidade de Franca. Pós-graduação Lato Sensu em Docência na Educação Profissional e Tecnológica pelo IF Sudeste MG campus Rio Pomba. E-mail: alinemaganin@ hotmail.com
} 
institution. Distance education allows the student to find the appropriate time, as well as use the available physical space to graduate or continue their training.

KEYWORDS: Distance Education; Pedagogy; Continuing Education.

\section{INTRODUÇÃO}

Pereira, Moraes e Teruya (2017) apontam que a Educação à Distância acontece quando o professor e o aluno estão separados no tempo ou no espaço, enfatizando mais a distância no espaço e propondo que a educação seja oferecida através do uso de tecnologias de telecomunicação e de transmissão de dados, com a utilização de voz e imagens. Os autores ressaltam que todas essas tecnologias, atualmente, são utilizadas por meio de um computador ou aparelhos tecnológicos.

Para Pereira, Moraes e Teruya (2017), a democratização do acesso à educação é compreendida como uma forma de promover a cidadania e o desenvolvimento, principalmente em países mais pobres, recomendando a adoção de práticas educacionais mais flexíveis, com o uso de Tecnologias da Informação e Comunicação. Por isso, é fundamental um sistema de ensino que apresente um novo modelo, mais flexível e adequado, que evite desperdícios de recursos humanos e materiais.

Atualmente, é possível considerar que o próprio saber se tornou uma mercadoria, a ser produzida e vendida sob condições que são cada vez mais organizadas em bases competitivas. Contudo, o ensino deve ser democrático, buscando alternativas para que atinja o maior número de pessoas, proporcionando acesso a uma educação de qualidade (PEREIRA; MORAES; TERUYA, 2017).

Oliveira (2017) aponta que a Educação à Distância torna possível que indivíduos possam adquirir ou aumentar sua formação, estando mais preparado para o mercado de trabalho. Em meio a diversos cursos e modalidades, aborda-se aqui a Pedagogia, que possui um vasto campo de atuação, desde instituições escolares até não escolares, atingindo os mais distantes municípios brasileiros, principalmente com a Educação à Distância.

Tozetto (2021) considera a importância da formação continuada, que deve se apresentar não como uma reciclagem, mas como uma qualificação para novas funções da escola e do professor. Assim, a formação continuada oportuniza o aprofundamento e conhecimento a novos conceitos, ampliando a situação de análise do ensino e contribuindo para o desenvolvimento do profissional e da instituição na qual ele está inserido.

Dessa forma, a Pedagogia constitui um dos cursos de graduação mais democráticos do país, oferecendo diversas contribuições para um mundo melhor. Poucos cursos de formação profissional 
são capazes de compor as culturas locais, criando cidadãos preparados e conscientes, oferecendo rumos às crianças e ampliando as possibilidades de conquistar a dignidade humana (OLIVEIRA, 2017).

Dentro desse contexto, assume-se como problema: De que forma a Educação à Distância pode contribuir para a formação continuada do profissional de Pedagogia?

Levanta-se a seguinte hipótese: A Educação à Distância constitui uma ferramenta eficiente na graduação e formação continuada do profissional de Pedagogia.

O presente trabalho se justifica por compreender que as práticas da Educação à Distância deixaram de ser um assunto periférico e assumiram um lugar de destaque no cenário da educação brasileira e na educação mundial (PEREIRA; MORAES; TERUYA, 2017). Considerando o pedagogo, compreende-se que esse profissional deve estar em constante formação, para que possa atuar de forma satisfatória tanto em ambientes escolares como em não escolares.

Com isso, entende-se que a Educação à Distância pode auxiliar esse profissional em sua formação, compreendendo que muitos não dispõem de tempo para frequentar cursos oferecidos de forma física, podendo cursar matérias de modo remoto, utilizando a tecnologia para se graduar ou continuar seus estudos, sem deixar de adquirir uma educação de qualidade.

A metodologia consiste na pesquisa bibliográfica, definida por Marconi e Lakatos (2011) como o levantamento da bibliografia publicada em forma de livros, revistas, publicações avulsas e imprensa escrita. Esse tipo de pesquisa possui como finalidade colocar o pesquisador em contato com o que foi escrito sobre determinado assunto. Dessa forma, foram coletadas obras em formas de livros, artigos e materiais disponíveis na internet, em bases de dados como SciELO e Google Acadêmico.

A pesquisa foi realizada utilizando os seguintes descritores: Pedagogia, Educação à Distância, Formação Continuada. As obras encontradas foram analisadas e selecionadas aquelas que se encaixavam nos seguintes critérios de inclusão: obras disponibilizadas gratuitamente, obras completas, artigos originais e de revisão publicados em língua portuguesa. Foram excluídas as obras incompletas e que com acesso restrito. Após a análise das obras, passou-se à escrita do trabalho.

O trabalho tem como objetivo geral: analisar a importância da Educação à Distância na formação do profissional de Pedagogia. Como objetivos específicos, apresentam-se: conceituar e compreender as particularidades da Educação à Distância; Estudar a formação do pedagogo; analisar a importância da formação continuada. 


\section{REVISÃO DE LITERATURA}

\section{EDUCAÇÃO À DISTÂNCIA: CONCEITOS E ESPECIFICIDADES}

A centralidade da educação foi, de forma estratégica, reafirmada através de documentos oficiais e da definição de políticas governamentais, exigindo novas competências e demanda a níveis superiores de escolaridade. A educação tornou-se, então, um processo para toda a vida, e todo ambiente foi caracterizado como um local de aprendizagem, buscando adequar o indivíduo ao mercado de trabalho. Assim, reafirma-se a importância do sistema de ensino, que passou a exigir novos modelos, mais flexíveis e adequados à realidade do aluno, evitando desperdício de recursos humanos e materiais (PEREIRA; MORAES; TERUYA, 2017).

Pereira, Moraes e Teruya (2017) consideram que o acesso à educação deve ser democratizado, promovendo a cidadania e o desenvolvimento do indivíduo, principalmente em países mais pobres. Para isso, tornam-se necessárias práticas educacionais mais flexíveis, com o uso de Tecnologias da Informação e Comunicação (TICs). A presença das TICs na educação proporcionou uma reorganização do trabalho didático, configurando uma nova realidade de educação, denominada Educação à Distância $(\mathrm{EaD})$.

A EaD pode ser definida como um sistema tecnológico de comunicação bidirecional capaz de substituir a interação pessoal em sala de aula como uma forma preferencial de ensino, acarretando, assim, em uma ação sistemática e conjunta de diversos recursos didáticos, contando com o apoio de uma organização tutorial, propiciando a aprendizagem autônoma dos estudantes (PEREIRA; MORAES; TERUYA, 2017).

Hack (2011) considera que, na sociedade atual, existe uma constante necessidade de atualização, considerando as mudanças sociais que fazem com que profissionais continuem sua formação educacional. Contudo, as atividades sociais impossibilitam que indivíduos dediquem tempo específico para voltarem à sala de aula e, assim, a EaD se torna uma ferramenta fundamental de aprendizagem e formação profissional, já que constitui uma forma de ensino capaz de atingir um grande número de pessoas, rompendo com o modo tradicional de ensino e apontando para um novo paradigma.

A EaD é, portanto, uma forma de ensino e aprendizagem que proporciona ao aluno que não possui tempo para comparecer fisicamente às aulas, a oportunidade de se apropriar de conteúdos transmitidos de forma não presencial, possibilitando eliminar as distâncias geográficas e temporais e proporcionando ao aluno a organização do seu tempo e local de estudos (HACK, 2011). 
De acordo com Martins e From (2020), a maioria dos estudantes de EaD apresentam características como: adultos já inseridos no mercado de trabalho, residentes em locais distantes dos núcleos de ensino, não conseguem aprovação em cursos regulares, não possuem tempo para estudar de forma presencial e, assim, precisam de um ensino flexível que atenda a suas necessidades.

No artigo 80 da Lei de Diretrizes e Bases da Educação Nacional (n 9394/96), a educação à distância foi definida como um modo de ensino que favorece a autoaprendizagem, com a medição de recursos didáticos organizados sistematicamente. Além disso, estabelece que o Poder Público deverá incentivar o desenvolvimento e a veiculação de programas de ensino à distância, em todos os níveis e modalidades de ensino e de educação continuada (BRASIL, 2021).

O artigo 62 da Lei de Diretrizes e Bases da Educação Nacional estabelece que a formação continuada e a capacitação dos profissionais de magistério poderão utilizar recursos e tecnologias de educação à distância. Além disso, deverá ser garantida a formação continuada para os profissionais no local de trabalho ou em instituições de educação básica e superior, incluindo os cursos de educação profissional, cursos de graduação, tecnológicos e de pós-graduação. Já o artigo 63 estabelece que os institutos superiores de educação deverão manter programas de educação continuada para os profissionais de educação dos diversos níveis (BRASIL, 2021).

A EaD deverá constituir, no futuro, uma parte natural da escola e da universidade, sendo definitiva a utilização da tecnologia, mantendo a proposta de socializar a informação, transmitindoa de forma hábil e proporcionando novos métodos de aprendizagem e avaliação (HACK, 2011).

É uma modalidade de realização do processo de construção do conhecimento de modo crítico, criativo e contextualizado que, quando não se torna possível o encontro presencial do educador e do aluno, deve ser promovida, então, a comunicação educativa através de múltiplas tecnologias que se tornam auxiliares do aprendizado (HACK, 2011).

A Educação a Distância é uma forma mais acessível de todas as modalidades de ensino, pois se utiliza de tecnologias e de metodologias especificas que ultrapassam obstáculos temporais e geográficos para a construção e democratização do aprendizado. Ela tem se desenvolvido em função de um contexto social, no qual a influência tecnológica reordenou valores e práticas pedagógicas necessárias para o ensino e para a aprendizagem (MARTINS; FROM, 2020 p. 07).

Dessa forma, Martins e From (2020) esclarecem que a EaD se torna bastante acessível, considerando a utilização de métodos que não se limitam ao tempo e ao espaço disponíveis, fazendo com que o aluno encontre a melhor forma de estudar e desenvolver o seu conhecimento. Com o avanço tecnológico, o ensino à distância proporciona uma junção de novas práticas pedagógicas com o acesso às tecnologias. 
A $\mathrm{EaD}$ possui características como autonomia, comunicação e processo tecnológico. A autonomia propicia que o aluno defina melhor o horário e local de estudo, conforme seu próprio ritmo e aprendizado, através de materiais didáticos que buscam facilitar o conhecimento e promover a autoaprendizagem (COSTA, 2020).

Em relação à comunicação, a Educação à Distância pode ocorrer em sincronia, quando estudantes e professores se encontram conectados ao mesmo tempo, através de webconferências e audioconferências, e também fora de sincronia, quando estudantes e professores não se encontram conectados ao mesmo tempo, em fóruns ou através de mensagens eletrônicas (MARTINS; FROM, 2020).

Para Martins e From (2020), essas formas de comunicação atendem um maior número de estudantes de diversas regiões. No aspecto tecnológico, considera-se que as diversas tecnologias são colocadas à disposição dos estudantes e professores, facilitando a comunicação.

Outra definição de EaD é proposta por Costa (2020), caracterizando essa modalidade como uma forma de educação onde professores e alunos estão separados, mas que utilizam diversas tecnologias de comunicação. Nessa definição, são destacados três pontos: separação no espaço, separação no tempo e planejamento.

Estudante e professor, ou aluno e aluno, não se encontram presentes no mesmo local, como no ensino presencial, estando separados fisicamente, mas com a possibilidade de troca de conhecimento. Esses recursos tecnológicos ainda favorecem que professores e alunos, mesmo não estando no mesmo momento conectados, possam trocar informações. Para isso, a EaD deve ser planejada pela instituição de ensino, incluindo o acompanhamento e a supervisão da aprendizagem pelos professores (COSTA, 2020).

A internet tornou possível a educação online, permitindo a ligação de vários computadores e oferecendo a interação entre textos, imagens e sons, abrindo grandes possibilidades para a EaD (VERGARA, 2007). As linguagens interativas estão cada vez mais sendo colocadas à disposição dos estudantes, com a EaD disponibilizando textos, orientações dos professores, bibliotecas e avaliações, com arquivos nos formatos de apresentações, planilhas, animações interativas e textos, sendo possível compreender que muitos dos materiais utilizados na EaD podem nutrir cursos presenciais (VERGARA, 2007).

Contudo, considera-se que podem ocorrer limitações tecnológicas, como baixa capacidade do computador utilizado ou lentidão no acesso. É possível considerar, ainda, as habilidades dos estudantes para lidarem com o computador e com a metodologia da EaD (VERGARA, 2007).

No Brasil, são valorizados os contatos físicos, com uma cultura fortemente relacional. Com isso, o trabalho fisicamente solitário pode ser caracterizado como uma limitação. Considera-se 
ainda que, tarefas pouco claras, podem ser um fator de limitação à EaD. Por isso, os estudantes precisam obter observações sobre as atividades desempenhadas, tendo sempre o auxílio das equipes de professores (VERGARA, 2007).

Outra limitação apontada por Vergara (2007) diz respeito à leitura e interpretação de textos e demais códigos linguísticos, caso o estudante não tenha habilidade desenvolvida ou se possui pouco domínio na utilização de recursos multimídia. Com isso, o conteúdo da $\mathrm{EaD}$ deve ser formulado de modo diferente da de um texto impresso.

Entretanto, mesmo existindo essa diferenciação, é possível ainda que exista problemas relacionados à compreensão dos textos. Esses problemas podem ser corrigidos através de uma linguagem clara e simples, utilizando um conteúdo consistente (VERGARA, 2007).

O papel do tutor é de extrema relevância nesse processo. A presteza nas respostas ao aluno é fundamental, já que não existe o contato presencial. O tutor acompanha e monitora atividades sincrônicas e as assincrônicas. Tutores devem ter a capacidade de provocar nos alunos a vontade consciente de compartilhamento de reflexões e compreensões e a ação neste sentido e, dessa forma, instigar a construção do conhecimento coletivo. A EAD exige autodisciplina, liberdade acompanhada da responsabilidade. É de relevância estar atento a alunos que não se comprometem com o ensino, monitorando-os e incentivando-os a prosseguir (VERGARA, 2007 p. 07).

Soares (2021) afirma que os professores devem estar capacitados para atuarem no ensino à distância, principalmente na utilização de novas tecnológicas, dominando o conteúdo de forma didática e apresentar novas formas de aprendizagem, mantendo a concentração e motivação em suas aulas, incentivando os estudantes. Com isso, a adaptação dos professores que passam do ensino presencial para o ensino virtual constitui uma dificuldade, considerando que as práticas educativas são diferentes, dificultando a forma de educar. Além disso, os professores ainda precisam adequar as novas estratégias didáticas e pedagógicas.

Além do exposto, Oliveira, Santos e Almeida (2021) apontam que o processo educacional à distância apresenta um computador como um membro entre aluno e professor. Assim, a atividade que antes era realizada copiando informações em um caderno, passa a exigir entradas no sistema, encaminhamento de atividades por postagens, participação em fóruns e exercícios virtuais.

A falta de treinamento dos alunos ao iniciarem um curso à distância, associada à falta de base para aprendizagem e conhecimento das tecnologias, faz com que os alunos encontrem dificuldades nessa forma de ensino. Além disso, deve-se respeitar as diferenças culturais de cada aluno, considerando suas dificuldades tecnológicas (OLIVEIRA; SANTOS; ALMEIDA, 2021). 
Souza et al. (2021), consideram que o tutor deve oferecer uma ação orientadora, articulando a instrução e o educativo. Para isso, precisa desenvolver e potencializar as capacidades básicas dos alunos, orientando-os a obterem crescimento intelectual e autonomia para tomar decisões, considerando seus desempenhos e suas circunstâncias de participação como aluno. Deve ainda, garantir um atendimento personalizado e contínuo, viabilizando a articulação necessária entre os elementos do processo e a execução dos objetivos propostos.

É importante considerar que cada instituição precisa construir seu modelo tutorial, buscando atender as exigências locais e regionais. Com isso, o tutor, respeitando a autonomia de aprendizagem de cada aluno, deverá estar constantemente orientando, dirigindo e supervisionando o processo de ensino-aprendizagem, considerando que, é através do tutor, que se garantirá a efetivação do curso em todos os níveis (SOUZA, et al. 2021).

Segundo Bastos (2017), atualmente existe uma infinidade de cursos via $\mathrm{EaD}$, que vão desde a Educação Básica até a universidade, oferecidos para aqueles que deixaram de frequentar o curso na etapa adequada. Os cursos $\mathrm{EaD}$ proporciona que o estudante adquira conhecimento suficiente na área de informática, dominando as ferramentas tecnológicas que lhes são exigidas. Assim, o estudante aumenta os conhecimentos, compreendendo que não se pode medir sua importância nos dias atuais.

Tudo isso são modos de lidar com a construção e efetivação do conhecimento e seus impulsos, que exigem estratégias e ações inéditas para os indivíduos. Dessa forma, os cursos de formação em $\mathrm{EaD}$ são verdadeiras alternativas para aqueles que desejam ter uma formação, mas não dispõem das condições necessárias exigidas pelo ensino presencial ou tempo para seguir o calendário da instituição (BASTOS, 2017).

\section{A FORMAÇÃO PROFISSIONAL EM PEDAGOGIA}

É importante considerar que, resgatar a história do curso de Pedagogia, é resgatar as diversas identidades dos pedagogos, assim como sua formação. O curso de Pedagogia, historicamente, sofreu inúmeras modificações em seus programas de ensino, nos seus objetivos, propostas pedagógicas e organizações curriculares, interferindo na formação profissional do pedagogo (GALLO, 2009).

O curso de Pedagogia foi estruturado em 1939, instituído pelo decreto-lei no 1190 de 04 de abril, que não foi considerando eficiente, visto que o curso não contava com um mercado profissional para o receber e, dessa forma, pedagogos eram formados, mas não encontravam campo de trabalho para sua atuação (GALLO, 2009). 
Contudo, Gallo (2009) explica que, em 1946, o decreto-lei 8530, instituiu como finalidades do ensino normal, prover a formação docente necessária às escolas primárias, habilitar administradores escolares para essas escolas, desenvolvendo e propagando os conhecimentos e técnicas relativas à educação na infância. Com isso, os regentes primários se formavam em quatro anos, atuando nas escolas Normais Regionais.

Para Teixeira e Machado (2009), o parecer CFE nº 252/69, incorporado à Resolução no 2/69 fixou os conteúdos mínimos que devem ser observados para organizar o curso de Pedagogia, que até hoje se encontra em vigor, baseando-se na concepção de que as diversas habilitações devem ter uma base comum de estudos, compreendendo matérias consideradas básicas para a formação de profissionais que irão atuar na área da educação, além de uma parte diversificada, atendendo às habilitações específicas.

Dessa forma, a base comum foi composta pelas disciplinas sociologia geral, sociologia da educação, psicologia e educação, história da educação, filosofia da educação e didática. (TEIXEIRA; MACHADO, 2009).

Segundo Fusari et al. (2017), a promulgação das Diretrizes Curriculares Nacionais para o curso de graduação em Pedagogia não contemplou as posições antagônicas, sacramentando sua centralidade na formação de professores para os anos iniciais do Ensino Fundamental e para a Educação Infantil.

Contudo, essa formação foi ampliada, contemplando a formação de professores no exercício das funções de magistério na Educação Infantil e nos anos iniciais do Ensino Fundamental, nos cursos de Ensino Médio, na modalidade Normal, de Educação Profissional na área de serviços e no apoio escolar, além de outras áreas nas quais sejam previstos conhecimentos pedagógicos (FUSARI, et al. 2017).

Além disso, Fusari, et al. (2017) explicam que a formação em Pedagogia contempla a participação na organização e gestão de sistemas e instituições de ensino, abrangendo o planejamento, execução, coordenação, acompanhamento e avaliação de tarefas próprias do setor da educação, assim como o planejamento, execução, coordenação, acompanhamento e avaliação de projetos e experiências educativas não escolares, abrangendo também a produção e difusão do conhecimento científico e tecnológico do campo educacional, em contextos escolares e não escolares.

Dessa forma, pode ser observado que a atuação profissional do pedagogo abrange um grande campo, excedendo o exercício da docência, cuja formação prepara o profissional para atuar na gestão educacional e em espaços nãos escolares (FUSARI, et al. 2017). 
Teixeira e Machado (2009) consideram que todo trabalho docente constitui um trabalho pedagógico, contudo, não é todo pedagogo que necessita ser professor, tratando-se de uma epistemologia do conhecimento pedagógico. Considera-se, assim, a abrangência do campo conceitual e prático da Pedagogia como uma reflexão sistemática sobre o campo educativo, reconhecendo a prática social como uma imensa variedade de práticas educativas e práticas pedagógicas.

Precisamos pensar em uma educação que seja transformadora e que os estudantes de Pedagogia sejam também formados para garantir a educação, com vistas à inclusão plena dos segmentos historicamente excluídos dos direitos sociais, culturais, econômicos e políticos. Nessa concepção o Pedagogo, tendo formação e atuação voltada para o aspecto social, precisa proporcionar os meios necessários para os sujeitos historicamente excluídos terem as condições de alcançarem a consciência crítica perante o contexto em que estão inseridos e a partir de suas ações, alcançarem seus direitos como cidadãos (TEIXEIRA; MACHADO, 2009 p. 231).

O curso de Pedagogia deve ser voltado para a formação de profissionais aptos para atuarem nos mais variados campos educativos, tanto formais quanto informais, e não apenas na gestão administrativa e pedagógica, mas também propondo e analisando de forma crítica as políticas educacionais, em diferentes contextos. Os profissionais de Pedagogia podem, ainda, atuar em campos como em programas sociais, serviços para terceira idade, lazer e animação cultural, editoria e requalificação profissional (LIBÂNEO, 2001).

A pedagogia, desde sua origem, passou por reformulações e atuações de seus profissionais, favorecendo uma dificuldade na construção da identidade do pedagogo, tanto por ele quanto por seus companheiros de trabalho. Mas, mesmo com essas dificuldades, foi aberta uma ampla discussão sobre a identidade do profissional de Pedagogia, através de associações e por meio de leis (GALLO, 2009).

Com o parecer 252/69, o curso de Pedagogia foi readequado, na tentativa de caracterizar a identidade do pedagogo conforme sua atuação no mercado de trabalho, estabelecendo uma base nacional comum. Dessa forma, torna-se possível perceber a importância das mudanças curriculares na formação do pedagogo, que influencia diretamente na construção de sua identidade, assim como na percepção que se possui sobre sua função e atuação profissional (GALLO, 2009).

A importância da formação continuada

Branco (2020) entende que o conhecimento é constituído por um conjunto de teorias que envolve os conteúdos específicos das disciplinas, que são resultantes da experiência acumulada da 
humanidade e sistematizada pela escola. O conhecimento histórico, a importância histórica e social dos conteúdos que proporciona avanços e validade para o ensino nos dias atuais.

O conhecimento das concepções pedagógicas possui grande relevância, visto que sustentam a ação educativa. Esses conhecimentos devem ser adquiridos de modo consistentes, articulados à prática, e não existe melhor prática do que uma boa teorização (BRANCO, 2020).

Não desconsiderando a importância da prática, é necessário ressaltar a teoria, não apenas para a reflexão sobre novas possibilidades de conhecimento, mas também para uma análise da própria prática. Sem a formação de uma teoria sólida, não há como realizar uma análise histórica buscando compreender a profissão, a escola e o conhecimento no contexto social vigente (BRANCO, 2020).

O ensino, acompanhamento e avaliação na escola apresentam desafios que apontam para a necessidade de um trabalho consciente, que contribua com a construção de uma sociedade mais justa. É fundamental profissionais comprometidos em realizar uma leitura da realidade, capaz de organizar situações de ensino onde as interações com o conhecimento possam proporcionar uma transformação da informação do senso comum em uma abordagem científica (TOZETTO, 2020).

O professor não deve se limitar a apenas transmitir determinado conteúdo, mas contar com uma formação continuada onde deve ser considerada a ação profissional em sua amplitude e complexidade, de forma contínua e concreta (TOZETTO, 2020).

Os problemas relacionados à formação de profissionais apenas podem encontrar soluções se for possível compreender que formação e profissionalização são aspectos que estão entrelaçados e profundamente relacionados à escolha da profissão, na forma de ingresso no campo de atuação, no acolhimento no local de trabalho, nas formas de organização e produção do trabalho, no grau de satisfação profissional com a carreira e com a profissão e nas perspectivas de crescimento e desenvolvimento profissional (SALDANHA; FRAGA, 2020).

O conhecimento, não é apenas nos livros que encontramos, mas nos diálogos, nas trocas de experiência, onde a nossa reflexão deve ser constante. Além disso, se tem discutido muito a respeito da formação continuada, que deve abandonar o conceito de formação docente como processos de atualização que se dão através da aquisição de informações científicas e didáticas, para adotar um conceito de formação que consiste na construção de conhecimentos e teorias sobre a prática, a partir da reflexão crítica (SALDANHA; FRAGA, 2020 p. 04).

Considerando a formação de profissionais de educação, Saldanha e Fraga (2020) apontam que é necessário compreender os objetivos dos diversos níveis e modalidades de ensino, assim como as características de cada fase do desenvolvimento do aluno, tendo como fundamentos: a 
associação entre teorias e práticas, inclusive mediante a capacitação em serviço e; o aproveitamento da formação e experiências anteriores em instituições de ensino.

Contudo, para que o profissional de ensino esteja apto para praticar o conceito de reflexão, ele deve estar aberto a novas formas de exercer sua profissão, modificando a forma de trabalhar os seus conhecimentos, visto que a prática deve proporcionar a reflexão, oferecendo uma visão mais crítica sobre sua atuação como educador (SALDANHA; FRAGA, 2020).

Nesse contexto, a formação continuada do profissional de ensino deve ser concebida através de reflexão, pesquisa, ação, descoberta, organização, fundamentação, revisão e construção teórica, e não apenas como uma forma de aprendizagem de novas técnicas, atualização em novas receitas pedagógicas ou aprendizagem das últimas inovações tecnológicas. A formação permanente, segundo essa concepção, é iniciada pela reflexão crítica sobre a prática (FREITAS; MACHADO, 2020).

De acordo com os autores acima citados, os grandes desafios referentes à formação continuada estão relacionados à fragmentação de estudos ou programas de formação oferecidos e a grande rotatividade de gestores pedagógicos, administrativos e professores.

Existem grandes problemas na efetivação de uma formação continuada que proporcione resultados satisfatórios, considerando a pouca sintonia entre a formação continuada e as reais necessidades dos profissionais de ensino, considerando ainda a não participação desses profissionais nas decisões, na falta de acompanhamento sistematizado da prática pedagógica, na descontinuidade de políticas públicas direcionadas à formação continuada e nos baixos salários que levam a uma grande carga horária de trabalho (FREITAS; MACHADO, 2020).

Dentro desse contexto é importante abordar a Educação Profissional e Tecnológica, que apresenta grande complexidade no segmento da educação brasileira, oferecendo desde a educação básica, com cursos de formação inicial e continuada ou de qualificação profissional, até o nível médio, com cursos de educação profissional técnica e nível superior, com educação profissional tecnológica de graduação e pós-graduação (MAGALHÃES; GONZALEZ, 2020).

Magalhães e Gonzalez (2020) destacam que, na Educação Profissional e Tecnológica, existe a possibilidade de escolha, por parte do aluno, da sua direção formativa, conforme suas aspirações profissionais ou de prosseguimento dos estudos, podendo escolher em qual área de ensino irá concentrar maior carga horária. Por isso, há a necessidade da continuidade de políticas públicas, valorizando os profissionais de ensino e ampliando a oferta de Cursos Superiores de Tecnologia, garantindo maior qualidade no ensino. 


\section{A IMPORTÂNCIA DA EAD NA FORMAÇÃO DO PEDAGOGO}

De acordo com Sousa, Granjeiro e Araújo (2013), a Educação à Distância constitui um modelo de ensino dinâmico, rápido, completo e eficiente, funcionando através da tecnologia, que atua como intermediário tecnológico onde o estudante deve ter acesso a um tutor, que orientará e coordenará os passos que devem ser seguidos, utilizando a interação por meio da internet e aparelhos tecnológicos, mesmo separados fisicamente.

Dessa forma, o ciberespaço assume uma característica de aprendizagem, considerando assim, a proposta da EaD como pedagogicamente correta. Contudo, é preciso compreender que ela não existe para substituir o modelo presencial, mas para agregar esforços, melhorando a qualidade da educação (SOUSA; GRANJEIRO; ARAÚJO, 2013).

O curso de Pedagogia, mesmo realizado à distância, na concepção de Sousa, Granjeiro e Araújo (2013), mantém a preocupação com articulação de objetivos, conteúdos e com todo o processo pedagógico. Com isso, a importância da EaD para a Pedagogia não pode ser resumida a um material instrucional com uma sequência de conteúdos onde o estudante pode assimilá-los, mas abrange uma formação completa que, por meio da tecnologia, prepara os alunos adequadamente para o mercado de trabalho.

Para os autores acima citados, a formação acadêmica do pedagogo passa inicialmente pelo curso de Pedagogia, compreendendo que, atualmente, existem muitas exigências para essa formação, principalmente para aqueles que já atuam na profissão.

A inovação tem se tornado uma ferramenta bastante eficiente, atendendo a procura pela formação através da flexibilidade de horários, onde o aluno pode conciliar suas atividades profissionais de forma mais tranquila (XAVIER, 2009).

Contudo, Sousa, Granjeiro e Araújo (2013) apontam que, no Brasil, há uma escassez de educadores que possuam a capacidade de conversar com as novas tecnologias da informação e comunicação, utilizando a internet de outras ferramentas de inovação. Mesmo com os dilemas enfrentados pelos cursos de formação de profissionais do ensino, torna-se necessário reconhecer que a $\mathrm{EaD}$ atua como um instrumento de inclusão profissional.

A falta de qualificação para o acompanhamento das necessidades e demandas educativas faz com que a $\mathrm{EaD}$ se torne um caminho possível de formação de profissionais capazes de responder e dialogas com as novas práticas de ensino e de aprendizagem (SOUSA; GRANJEIRO, ARAÚJO, 2013). 
Na compreensão de Sá (2007), a EaD não busca resolver as demandas da educação formal no Brasil, mas incorporar o desenvolvimento científico e tecnológico, democratizando o acesso ao conhecimento, oferecendo a possibilidade de estudo àqueles que não possuem condições econômicas ou tempo para isso.

A seriedade política e epistemológica de projetos e programas de $\mathrm{EaD}$ na formação de profissionais do ensino oferecerá maior credibilidade a essa modalidade, compreendendo que os objetivos dessa forma de ensino são os mesmos da educação presencial, mas apresenta características específicas, implicando em uma abordagem sistêmica organizacional, onde não existe a possibilidade de conhecer as particularidades das partes sem conhecer todo o conjunto (SÁ, 2007).

Alunos que frequentam cursos à distância, geralmente possuem na $\mathrm{EaD}$ a única oportunidade de formação superior, principalmente aqueles que residem em locais distantes das instituições de ensino superior. (PETERS, 2009). É possível compreender que a EaD não constitui uma formação amenizadora, visto que a realização dessa modalidade, mesmo com as dificuldades, torna possível modificar a prática docente, possibilitando, ainda, condições de formar profissionais de ensino cujas dificuldades nessa formação não são decorrentes da forma de ensino, mas das condições prévias de formação desses sujeitos (PETERS, 2009).

A tarefa dos pedagogos é extremamente complexa o que exige capacidade crítica, ética, compreensão do processo de aprendizagem, respeito às diferenças entre seus estudantes, entre outros e que para isso é preciso competência formativa e profissional, que se referem aos conhecimentos pedagógicos intelectuais adquiridos ao longo do processo formativo e a forma como serão produzidos. Assim, podemos entender que as competências envolvem um complexo de conhecimentos e habilidades que permitem a resolução de situações para as quais não se tem uma solução, tendo em vista utilizar este complexo na prática pedagógica o que possivelmente constitui a dimensão pedagógica da formação docente (CASTRO, 2013 p. 44).

A pedagogia possui como pressuposto a formação de um profissional pesquisador e, dessa forma, as atividades formativas devem ser direcionadas para a reflexão crítica com relação à comunidade escolar, compreendendo que a formação prática é a referência na formação oferecida, mesmo havendo necessidade de uma discussão mais articulada sobre a formação prática e como ela se articula ao longo do curso, principalmente em relação aos estágios supervisionados (OLIVEIRA, 2010).

O modelo de educação à distância apresenta a internet como o principal espaço de socialização e realização de atividades formativas e o tutor virtual deve ser caracterizado como um agente formador. Assim, as instituições de educação à distância devem criar políticas internas que 
atenda às propostas de $\mathrm{EaD}$, garantindo a continuidade dos cursos oferecidos nessa modalidade de ensino (OLIVEIRA, 2010).

\section{CONSIDERAÇÕES FINAIS}

Através da presente pesquisa foi possível conceituar a Educação à Distância como uma modalidade de ensino não presencial, onde o processo de ensino e aprendizagem ocorre através do uso da internet e aparelhos tecnológicos. Não é uma modalidade que procura substituir o ensino presencial, mas oferecer a oportunidade de estudo para aqueles que residem longe das instituições de ensino ou não possuem tempo disponível para estudar.

Muitos profissionais não conseguem conciliar o trabalho com os estudos, visto que as aulas no formato presencial exigem que os alunos frequentem fisicamente a instituição de ensino. Assim, muitos deixam de se graduar ou continuar sua formação, deixando de adquirir mais conhecimentos para atuação no mercado de trabalho.

Considero que o profissional já graduado e que trabalha, muitas vezes deseja continuar sua formação, adquirindo mais conhecimento sobre a profissão que desempenha e aumentando suas habilidades. Contudo, o tempo escasso impede que esse profissional alcance seus objetivos profissionais.

A educação à distância permite que o aluno encontre o tempo adequado, assim como utilize o espaço físico disponível para se formar ou dar continuidade à sua formação. Em relação ao pedagogo, o curso de Pedagogia pode ser realizado a modalidade EaD, assim como cursos de formação continuada, essencial para atuação plena do profissional de Pedagogia, que possui um grande campo de atuação, indo além do exercício da docência, visto que esse profissional deve possui a formação necessária para atuar na gestão educacional e em espaços não escolares e, para isso, a formação continuada é fundamental.

Foi possível compreender, ainda, que o pedagogo deve ter grande capacidade crítica e ética, deve ainda, compreender todo o processo de aprendizagem, respeitar as diferenças dos estudantes e, para isso, a formação continuada é essencial, pois poderá proporcionar novos conhecimentos pedagógicos. Assim, para o profissional sem tempo ou que resida em locais afastados das instituições de ensino, essa formação poderá ocorrer através da educação à distância.

Além do que aqui foi exposto, o presente estudo não termina aqui, deixando margem para novas pesquisas sobre o tema trabalhado. 


\section{REFERÊNCIAS}

BASTOS, M. A importância da EaD na formação do sujeito. Revista Científica Multidisciplinar Núcleo do Conhecimento, v. 14, n. 01, pp. 71-81, 2017. Disponível em: https://www.nucleodoconhecimento.com.br/educacao/ead-formacao. Acesso em: 20 fev. 2021.

BRANCO, C. Formação continuada de professores: focalizando a relação teoria e prática. Disponível em: http://www.gestaoescolar.diaadia.pr.gov.br/arquivos/File/producoes_pde/artigo_cris tina_branco.pdf. Acesso em: 27 dez. 2020.

BRASIL. Lei $\mathrm{n}^{0} 9.394$ de 20 de dezembro de 1996. Disponível em: http://www.planalto. gov.br/ccivil_03/leis/19394.htm. Acesso em: 18 fev. 2021.

CASTRO, A. Formação inicial de pedagogos na modalidade EaD: ambiência, competências e práticas. Dissertação. Universidade Federal de Santa Maria. Santa Maria, 2013. Disponível em: https://repositorio.ufsm.br/handle/1/7098. Acesso em: 20 fev. 2021.

COSTA, A. A educação à distância no Brasil: concepção, histórico e bases legais. Disponível em:https://www.unirios.edu.br/revistarios/media/revistas/2017/12/a_educacao_a_distancia_no_bras il_concepcoes_historico_e_bases_legais.pdf. Acesso em: 21 dez. 2020.

FREITAS, S; MACHADO, J. Formação continuada: um estudo colaborativo com professores do Ensino Médio. Revista Interações, v. 21, n. 01, pp. 141-153, 2020. Disponível em: https://www.scielo.br/scielo.php?script=sci_arttext\&pid=S1518-7012

2020000100141. Acesso em: fev. 2021.

FUSARI, J; PIMENTA, S; PEDROSO, C; PINTO, U. O Curso de Licenciatura em Pedagogia: fragilidades na formação inicial do professor polivalente. Revista Educação e Pesquisa, v. 43, n. 01, pp. 15-30, 2017. Disponível em: https://www.scielo.br/scielo.php?pid=S1517-97022017000 100015\&script=sci_abstract\&tlng=pt. Acesso em: 20 fev. 2021.

GALlO, M. A história da formação de pedagogos no curso de Pedagogia. Anais do IX Congresso Nacional de Educação. Curitiba, 2009. Disponível em: https://educere.bruc.com.br /cd2009/pdf/1918_979.pdf. Acesso em: 20 fev. 2021.

HACK, J. Introdução à educação à distância. Florianópolis: UFSC, 2011.

LIBÂNEO, J. Pedagogia e pedagogos, para quê? São Paulo: Cortez, 2001.

MAGAlHÃES, A; GONZALEZ, W. Desafios da educação profissional e tecnológica. Disponível em: https://www.comciencia.br/desafios-da-educacao-profissional-e-tecnologica-novasfaces-dos-mesmosproblemas/\#: :text=Observa\%2Dse\%20uma\%20grande $\% 20$ complexidade,com $\%$ 20a\%20educa\%C3\%A7\%C3\%A3o\%20profissional\%20tecnol\%C3\%B3gica. Acesso em: $27 \mathrm{dez}$. 2020.

MARCONI, Marina de Andrade; LAKATOS, Eva Maria. Metodologia do trabalho científico: Procedimentos básicos, pesquisa bibliográfica, projeto, relatório, publicações e trabalhos científicos. São Paulo: Atlas: 2011. 
MARTINS, K.; FROM, D. A importância da educação à distância na sociedade atual. Disponível em: https://www.assessoritec.com.br/wp-content/uploads/sites/641/2016/12/Artigo-Kari ne.pdf. Acesso em: 21 dez. 2020.

OLIVEIRA, E; SANTOS, L; ALMEIDA, L. Educação à distância: uma reflexão das dificuldades dos egressos do Ensino Médio das escolas públicas ao ingressarem no ensino superior à distância ocasionando a evasão. Disponível em: https://facsaopaulo.edu.br/wp-content/uploads/sites/ 16/2018/05/ed1/6.pdf. Acesso em: 19 fev. 2021.

OLIVEIRA, F. Formação inicial de professores em cursos de Pedagogia a distância: indicadores do modelo formativo da UAB/UFSCar. Dissertação. Universidade Estadual Paulista Presidente Prudente, 2010. Disponível em: https://repositorio.unesp.br/handle/11449/92316. Acesso em: 20 fev. 2021.

OLIVEIRA, M. A Pedagogia além dos muros escolares. Monografia. Escola de Educação. Universidade Federal do Estado do Rio de Janeiro. Rio de Janeiro, 2017. Disponível em: http://www2.unirio.br/unirio/cchs/educacao/graduacao/pedagogiapresencial/MARIANADEOLIVEI RA.pdf. Acesso em 20 fev. 2021.

PEREIRA, M; MORAES, R; TERUYA, T. Educação à distância: reflexões críticas e práticas. Uberlândia: Editora Navegando, 2017.

PETERS, E. Um estudo sobre a formação de professores para os primeiros anos do Ensino Fundamental na modalidade a distância. Dissertação. Universidade Federal de Mato Grosso do Sul, 2009. Disponível em: http://bdtd.ibict.br/vufind/Record/UFMS_6b8dd5441aec90f3603238fe 95a1343d. Acesso em: 20 fev. 2021.

SÁ, R. Educação a distância. Dissertação. Universidade Estadual de Campinas. São Paulo, 2007.

SALDANHA, L; FRAGA, M. A importância da formação continuada para o bom desempenho do docente. Disponível em: https://www2.faccat.br/portal/sites/default/files/A\%20IMPORTANCIA\% 20DA\%20FORMACAO\%20CONTINUADA\%20PARA\%20O\%20BOM.pdf. Acesso em: 27 dez. 2020.

SOARES, N. Dificuldades apresentadas no ensino de educação à distância. Disponível em: https://educere.bruc.com.br/arquivo/pdf2017/24812_12508.pdf. Acesso em: 19 fev. 2021.

SOUSA, C; GRANJEIRO, M; ARAÚJO, R. Formação do pedagogo com educação à distância. Anais do XI Congresso Nacional de Educação. Curitiba, 2013.

SOUZA, C; SPANHOL, F; LIMAS, J; CASSOL, M. Tutoria na educação à distância. Disponível em: http://www.abed.org.br/congresso2004/por/htm/088-TC-C2.htm. Acesso em: 18 fev. 2021.

TEIXEIRA, E; MACHADO, E. Pedagogia: concepções e práticas em transformação. Revista Educar, v. 35, n. 01, pp. 223-236, 2009. Disponível em: https://www.scielo.br/pdf/er/n35/ n35a17.pdf. Acesso em: 20 fev. 2021.

TOZETTO, S. Docência e formação continuada. Disponível em: https://educere.bruc. com.br/arquivo/pdf2017/23503_13633.pdf. Acesso em: 27 dez. 2020. 
VERGARA, S. Estreitando relacionamentos na educação à distância. Cadernos EBAPE, v. 05, n. 01, pp. 01-08, 2007. Disponível em: https://www.scielo.br/scielo.php?script=sci_arttext\&pid =S1679-39512007000500010. Acesso em: 20 fev. 2021.

XAVIER, A. Letramento digital e ensino. Núcleo de Estudos de Hipertexto e Tecnologia Educacional. Universidade Federal de Pernambuco. Recife, 2009. Disponível em: http:// www.nehte.com.br/artigos/Letramento-Digital-Xavier.pdf. Acesso em: 19 fev. 2021. 